\title{
ОРГАНИЗАЦИОННЫЕ АСПЕКТЫ ОПЕРАТИВНОГО И ПРЕВЕНТИВНОГО ВНУТРЕННЕГО ФИНАНСОВОГО КОНТРОЛЯ В РАМКАХ РАСХОДОВАНИЯ СРЕДСТВ НА ФЕДЕРАЛЬНЫЕ ПРОЕКТЫ *
}

\author{
(C) 2020 Петров А. М. \\ доктор экономических наук, профессор Департамента бизнес-аналитики \\ Финансовый университет при Правительстве Российской Федерации, Россия, Москва \\ E-mail: palmi@inbox.ru \\ (c) 2020 Шнайдер О.В. \\ кандидат экономических наук, доцент Департамента бизнес-аналитики \\ Финансовый университет при Правительстве Российской Федерации, Россия, Москва \\ E-mail: OVSHnajder@fa.ru \\ (c) 2020 Бердникова Л.Ф. \\ кандидат экономических наук, доцент департамента магистратуры (бизнес-программ) \\ Тольяттинский государственный университет, Россия, Тольятти \\ E-mail: bleylaf@mail.ru
}

За последнее десятилетие система внутреннего финансового контроля в России претерпела значительный путь в своем развитии. Контроль выступает как одна из важнейших функций управления. В сфере управления финансовыми средствами внутренний финансовый контроль является неотъемлемой частью системы регулирования финансовых отношений. Так, необходимость в контроле финансово-хозяйственной деятельности субъекта хозяйствования объективно вытекает из сущности финансов как денежных отношений. Выполнение федеральных проектов связано с получением и расходованием денежных средств, а, следовательно, затрагивает интересы государства, партнеров и всех взаимосвязанных контрагентов. Организация процесса внутреннего финансового контроля включает в себя разработку локальных стандартов, формирование плана и программы проверок, определение мер по корректировке показателей и устранению выявленных нарушений. Оперативный и превентивный внутренний финансовый контроль призваны способствовать эффективному выполнению федеральных проектов, вовремя обнаружить различные нарушения и ошибки в части расходования средств, выявить недобросовестность сотрудников. Оперативный внутренний финансовый контроль позволяет установить текущие нарушения и оперативно разработать мероприятия по их устранению. Превентивный внутренний финансовый контроль направлен на предупреждение возможных ошибок и финансовых махинаций. Данный вид контроля способен предупреждать риски нарушений. Формирование эффективной системы внутреннего контроля в рамках расходования средств при выполнении федеральных проектов необходимо не только распорядителям средств, но и их получателям. Такая система представляет механизм получения необходимой информации о течении дел, соответствии выполняемой работы государственному заданию, а также законности проводимых операций по расходованию денежных средств в рамках исполнения федеральных проектов. В статье уточнены принципы формирования оперативного и превентивного внутреннего финансового контроля применительно к расходованию средств в рамках реализации федеральных проектов. Раскрыто содержание каждого такого принципа. Существенное внимание уделено требованиям к оперативному и превентивному внутреннему контролю при расходовании средств на федеральные проекты.

Ключевые слова: контроль, внутренний финансовый контроль, оперативный внутренний финансовый контроль, превентивный внутренний финансовый контроль, требования внутреннего финансового контроля, принципы, расходование средств, федеральные проекты, бюджет, организация внутреннего контроля.

\footnotetext{
* Статья подготовлена по результатам исследований, выполненных за счет бюджетных средств по государственному заданию Финансового университета
} 
К одной из важных задач управления средствами при реализации федеральных проектов относится организация оперативного и превентивного внутреннего финансового контроля с целью направления всех усилий на качественные преобразования, своевременное выявление нарушений и разработку мероприятий предотвращающих их наступление в будущем. Исследование теории и практики в области внутреннего контроля показывают, что существует две основные проблемы, с которыми сталкиваются субъекты хозяйствования в своей работе: «первая это полное или частичное отсутствие контроля, в связи с отсутствием нормативно-правового регулирования со стороны государства, вторая это не согласованная работа отделов компании, в связи с некомпетентностью персонала» [1]. Такие обстоятельства требуют развернутого исследования в части организации систем оперативного и превентивного внутреннего финансового контроля при расходовании средств в процессе реализации федеральных проектов.

Существенный вклад в развитие аудита, а также системы построения внутреннего финансового контроля внесли многие ученые как Д.С.Аболенский, Р.П.Булыга, Л.Ф.Бердникова, Л.И.Воронина, Ю.В.Гнездова, И.С.Егорова， В.Э.Керимов，А.В.Крикунов， Е.В.Никифорова, А.М.Петров, П.В.Селиванов, Г.А.Скачко, В.П.Суйц, А.Д.Шеремет и др. [1-17]. Однако в настоящее время не разработаны единые подходы, принципы и требования к организации оперативного и превентивного внутреннего финансового контроля в рамках расходования средств на федеральные проекты, что подтверждает актуальность темы исследования.

Основной целью данной статьи является раскрытие организационных основ оперативного и превентивного внутреннего финансового контроля в рамках расходования средств на федеральные проекты.

Эффективность функционирования хозяйствующего субъекта во многом зависит от наличия действенной системы внутреннего финансового контроля. Главенствующая роль при этом отводится оперативному и превентивному контролю. В свою очередь, качественное выполнение государственных заданий определяется регулярным контролем за ходом его реализации и законностью расходования средств в рамках федерального проекта. Рациональной и действенной система внутреннего контроля может быть только при правильной ее организации, наличии единых локальных стандартов, не противоречащих законодательству, а также соблюдении основных принципов и требований при проведении оперативных и превентивных контрольных мероприятий.

Считаем, что для формирования эффективной системы оперативного и превентивного инструментария внутреннего финансового контроля при расходовании средств в рамках федеральных проектов необходимо соблюдать ключевые принципы. Проведенное исследование позволило выделить такие принципы, соблюдение которых является необходимым условием при проведении оперативного и превентивного внутреннего финансового контроля расходных операций при выполнении федеральных проектов (рисунок 1). Рассмотрим их содержание.

Принцип законности раскрывает необходимость соблюдения законодательства Российской Федерации, а также локальных документов всеми работниками службы внутреннего финансового контроля.

Принцип ответственности закрепляет ответственность каждого работника службы внутреннего финансового контроля за совершаемые им действия или бездействие в случае обнаружения правонарушений и ошибок.

Принцип сбалансированности направлен на то, что в процессе осуществления контрольных функций необходимо соблюдать сбалансированность между средствами контроля и правами субъекта контроля.

Принцип оперативности предполагает, что работники службы внутреннего финансового контроля при выполнении оперативных контрольных мероприятий при выявлении нарушений должны своевременно извещать о них органы управления.

Принцип регулярности подразумевает, что проведение оперативного и превентивного внутреннего финансового контроля должно осуществляться на регулярной основе.

Принцип комплексности предусматривает, что при проведении внутреннего финансового контроля необходимо охватывать все направления, задействованные в рамках выполнения федеральных проектов.

Принцип объективности означает, что все внутренние контролеры при выполнении своих функций должны оценивать объекты контроля беспристрастно, объективно. 


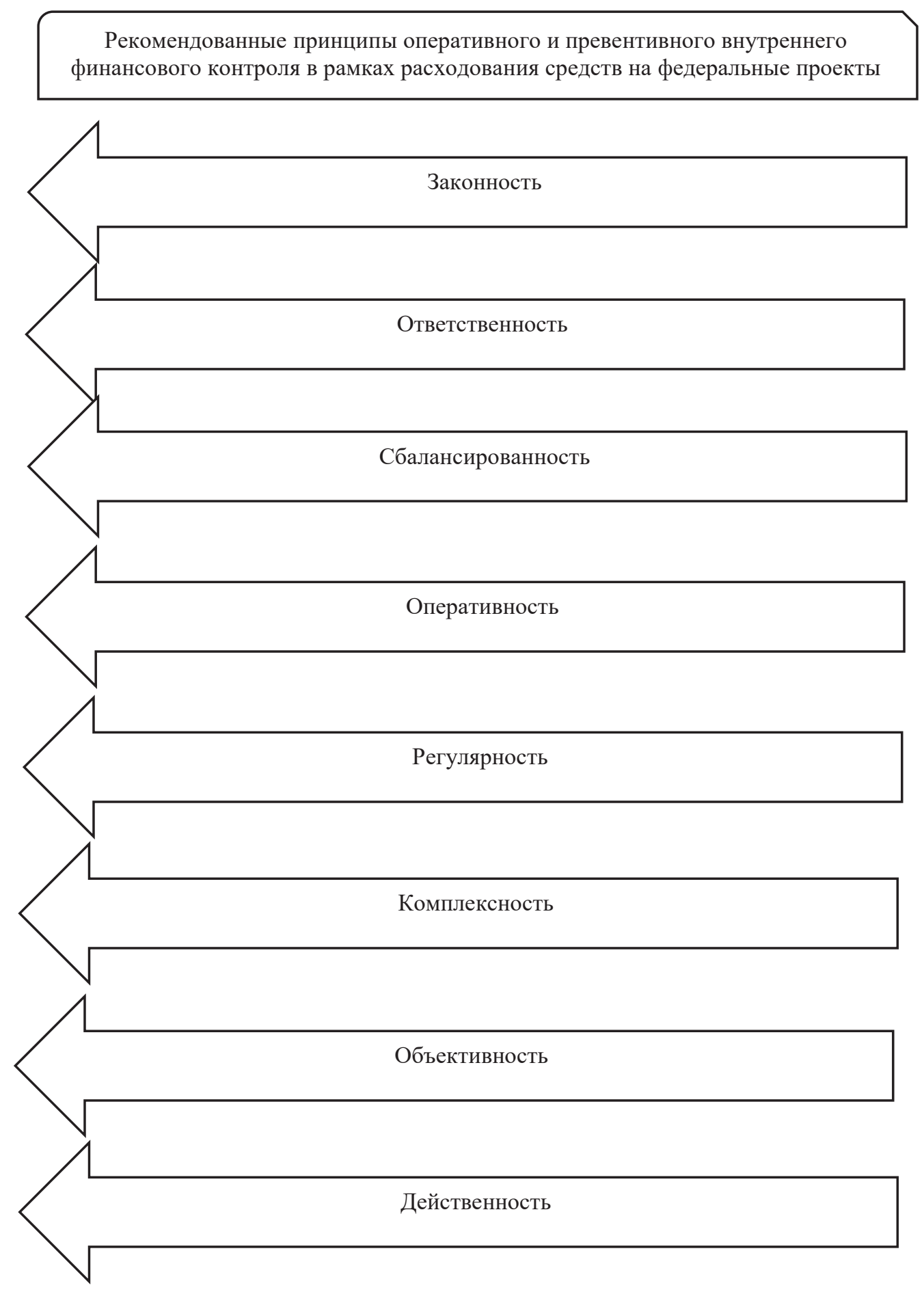

Рисунок 1. Рекомендованные принципы оперативного и превентивного внутреннего финансового контроля в рамках расходования средств на федеральные проекты 
Принцип действенности гласит, что процедуры оперативного и превентивного внутреннего финансового контроля должны быть действенными, эффективными, экономически оправданными.

Как было отмечено выше, эффективность оперативного и превентивного внутреннего финансового контроля определяется соблюдением основных требований (рисунок 2).

Требование заинтересованности администрации предполагает заинтересованность органов управления в эффективности и повышении качества внутреннего финансового контроля.

Требование компетентности работников внутреннего финансового контроля определяет высокий уровень профессионализма и честность работников внутреннего финансового контроля.

Требование развития и совершенствования направлено на регулярное совершенствование оперативного и превентивного внутреннего финансового контроля, ввиду изменения законодательства, влияния внешних и внутренних факторов.

Требование приемлемости методологии внутреннего финансового контроля предполагает возможность реализации всех методов и процедур внутреннего финансового контроля на практике.

Требование приоритетности направлено на необходимость ранжирования участников с высокой степенью риска и проверки их в первую очередь.

Требование рациональности предполагает, что все применимые процедуры, методы и мероприятия должны быть целесообразными.

Требование ответственности заключается в том, чтобы все сотрудники службы внутреннего финансового контроля осознавали собственную ответственность при выполнении профессиональных функций.

Требование регламентации предполагает, что все основные контрольные функции, процедуры и мероприятия должны быть официально оформленными и соответствовать установленным локальным документам.

Требование взаимодействия и координации ориентировано на взаимодействии всех структурных подразделений и участников федераль-
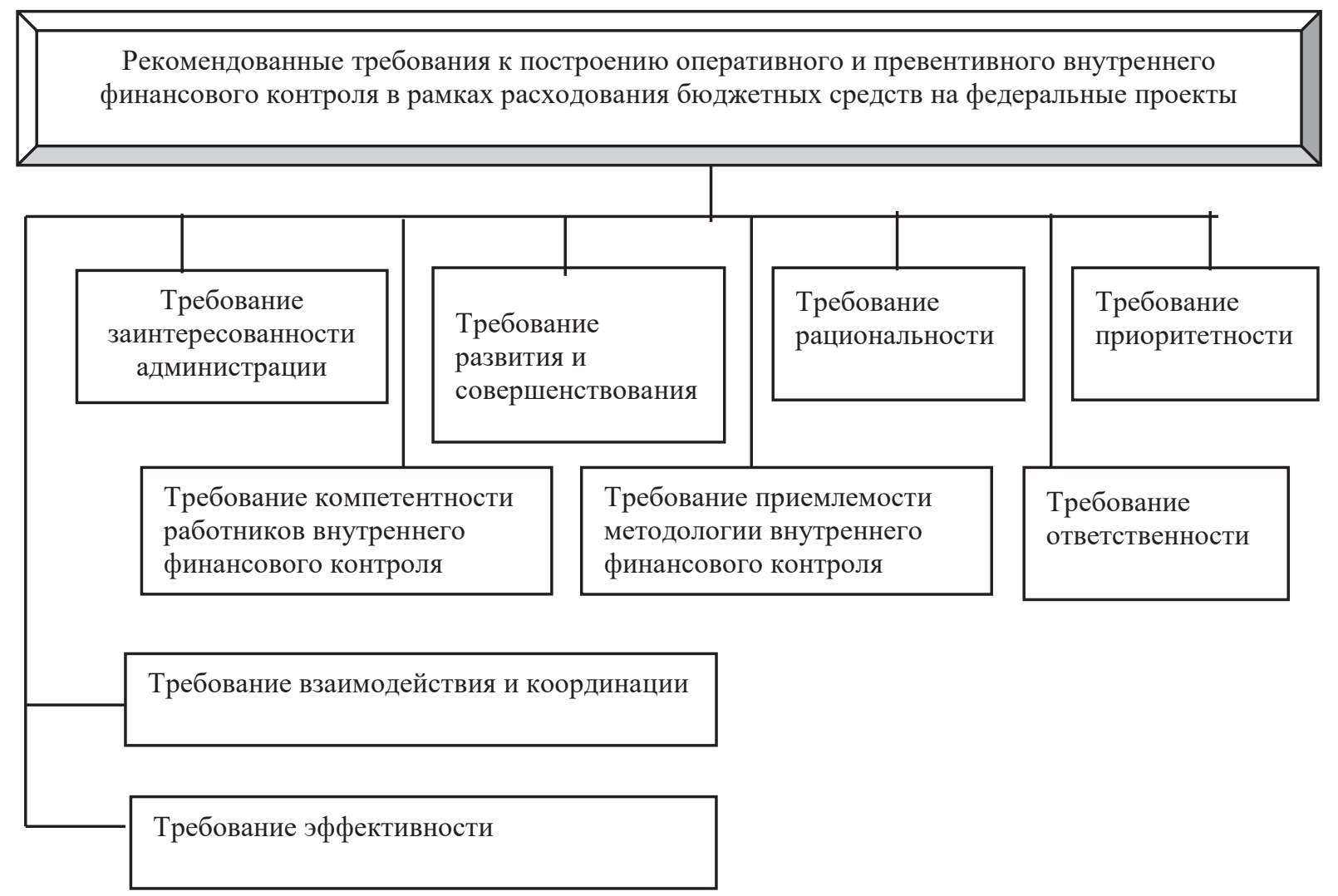

Рисунок 2. Рекомендованные требования оперативного и превентивного внутреннего финансового контроля в рамках расходования бюджетных средств на федеральные проекты 
ных проектов.

Требование эффективности означает, что все используемые методы и процедуры внутреннего финансового контроля, а также разработанные мероприятия должны быть эффективными и обоснованными.

В результате проведенного исследования необходимо отметить, что организация системы оперативного и превентивного внутреннего финансового контроля должна стать неотъемлемой частью деятельности каждого хозяйствующего субъекта. Особенно это относится к экономическим субъектам, осуществляющим расходование средств, связанных с выполнением федеральных проектов.

\section{Библиографический список}

1. Бердникова Л. Ф. Внутренний контроль в системе экономической безопасности: сущность, необходимость и основные проблемы / Л. Ф. Бердникова, Е. Н. Андриевская // Карельский научный журнал. 2018. № 1 (22). Т.7 C. 95-97.

2. Аудит крупных коммерческо-промышленных организаций: методология, теория и практика /Е.В. Никифорова, Л.Ф.Бердникова, Е.Б.Вокина, И.В.Шумилова // Аудит крупных коммерческо-промышленных организаций: методология, теория и практика: монография / Е.В.Никифорова [и др.].- Тольятти: Изд-во ТГу, 2012.- 144 c.

3. Булыга Р.П.Инновационные направления и процедуры аудита и контроля: учебник для студентов вузов, обучающихся по направлению подготовки «Экономика».- ЮНИТИ, 2018. - 159 с.

4. Вахорина, М.В.Управленческая отчетность как объект внутреннего аудита//Научные исследования и разработки. Экономика.-2014.- Т.2, № 6.- С. 8-11.

5. Воронина Л. И. Аудит: теория и практика. В 2 ч. Ч.2. Практический аудит: учебник. - Инфра-М, 2019. - 344 с.

6. Гнездова Ю. В. Государственный аудит в системе финансового контроля: учебник для магистрантов.- ЮНИТИ, 2017.- 151 с.

7. Егорова И. С. Аудит: учебное пособие.- КНОРУС, 2017. - 537 с.

8. Керимов В.Э. Бюджетирование и внутрихозяйственный контроль в торговле / В.Э. Керимов, Д.С. Аболенский, П. В. Селиванов.- М.: Эксмо, 2006.-224 с.

9. Никифорова Е. В. Об основах организации аудиторской проверки / Е.И. Никифорова, Л. Ф. Бердникова// Развитие методологии учета, анализа и контроля в условиях инновационной экономики. Декабрьские чтения имени С.Б.Барнгольц: сборник трудов Международной научно-методической конференции (Москва, 14-15 декабря 2010 года): в 3 т. / отв. ред. М. В. Мельник. Тольятти: ТГУ, 2010.- Т. III. - 276 с. - С. $53-61$.

10. Петров А.М. К вопросу организации внутреннего финансового контроля в рамках расходования средств на федеральные проекты/ А. М. Петров, К. Ю. Бурцева // Экономические науки, 2020, № 7 (188). С. $113-119$.

11. Петров А.М. Оперативный и превентивный инструментарий реализации внутреннего финансового контроля в рамках расходования средств на федеральные проекты/ А. М.Петров// Экономические науки, 2020, № 4 (185). С. 169-178.

12. Правовое регулирование финансового контроля в Российской Федерации: проблемы и перспективы: Монография / Отв. ред. Е. Ю. Грачева.- М.: Норма, 2013.

13. Скачко Г. А. Аудит: учебник.- Дашков и К, 2017.- 299 с.

14. Суглобов А. Е. Аудит: учебник / А. Е. Суглобов, Б. Т. Жарылгасова, В. Ю. Савин.- М.: Дашков и К, 2015.-368 с.

15. Суй В. П. Аудит: учебник.- КНОРУС, 2017. - 287 с.

16. Хаменушко, И. В. Валютный контроль в РФ: моногр. / И. В. Хаменушко.- М.: ФБК-Пресс, 2018. - 480 с.

17. Шеремет А. Д. Аудит: учебник.-ИНФРА-М.-2017.- 375 с.

18. Информация Минфина России N П3-11/2013 «Организация и осуществление экономическим субъектом внутреннего контроля совершаемых фактов хозяйственной жизни, ведения бухгалтерского учета и составления бухгалтерской (финансовой) отчетности»

19. Вокина Е.Б., БердниковаЛ.Ф., Аспекты аудита и экономического анализа интегрированной отчетности / Е. Б. Вокина, Л.Ф.Бердникова // Вектор науки Тольяттинского государственного университета. Серия: Экономика и управление. 2015.№ 4 (23). С. 23-28.

20. Бердникова Л.Ф. Внутренний контроль как инструмент выявления рисков и укрепления экономической безопасности организации / Л. Ф. Бердникова, Е. Б. Вокина// Вестник СамГУПС, 2018. № 2 (40). С. 67-70.

21. Петров А. М. «КОНТРОЛЬ ЗА ДВИЖЕНИЕМ ДЕБИТОРСКОЙ И КРЕДИТОРСКОЙ ЗАДОЛЖЕННОСТИ» Современный бухучет. 2004. № 9. С. 38. 
22. Карпова Т.П., Петров А.М., ГорбатковаГ.А., СамаринаЛ.Б., ДашкинаГ.Г., СидороваМ.И., Сабанин Р.Л., Ситникова В.А., ЛистопадЕ.Е. «БУХГАЛТЕРСКИЙ УЧЕТ В СФЕРЕ УСЛУГ» учебник для студентов высшего профессионального образования, обучающихся по специальности 080109 «Бухгалтерский учет, анализ и аудит» / Под редакцией М.А. Вахрушиной; Министерство образования и науки Российской Федерации, Федеральное государственное учреждение «Федеральный институт развития образования». Москва, 2011. Сер. Читай

23. Петров А.М., МельниковаЛ.А. «ФОРМИРОВАНИЕ ОТЧЕТНОСТИ В СООТВЕТСТВИИ С ТРЕБОВАНИЯМИ МСФО КАК ОБЪЕКТИВНАЯ НЕОБХОДИМОСТЬ НА СОВРЕМЕННОМ ЭТАПЕ РАЗВИТИЯ ЭКОНОМИКИ РФ» Проблемы современной экономики. 2017. № 2 (62). С. 105-107.

24. Петров А.М., Коняхин А.Н. «УЧЕТНАЯ ПОЛИТИКА ПРИ ПОДГОТОВКЕ ПЕРВОЙ ОТЧЕТНОСТИ СОГЛАСНО МСФО» Международный бухгалтерский учет. 2013. № 11 (257). С. 2-15.

25. Петров А.М., Лымарь М. П. «СОСТАВ БУХГАЛТЕРСКОЙ ОТЧЕТНОСТИ В РОССИИ И КИТАЕ» МеждУНароднЫЙ бухгалтерский учет. 2014. № 31 (325). С. 28-37.

26. Петров А.М., ЛымарьМ.П. «СРАВНИТЕЛЬНАЯ ХАРАКТЕРИСТИКА ОСНОВНЫХ ПОЛОЖЕНИЙ ЗАКОНОВ, РЕГУЛИРУЮЩИХ БУХГАЛТЕРСКИЙ УЧЕТ В КИТАЕ И РОССИИ» МеждународныЙ бухгалтерскиЙ учет. 2013. № 40 (286). С. 52-60.

27. Петров А.М., Лымарь М.П. «СРАВНИТЕЛЬНЫЙ АНАЛИЗ БУХГАЛТЕРСКОГО УЧЕТА АКТИВОВ В РОССИИ И КИТАЕ» Международный бухгалтерский учет. 2014. № 27 (321). С. 34-48.

28. Петров А.М. «ОБЩЕСТВЕННОЕ ПИТАНИЕ 6 в 1: учетная политика, документооборот, калькулирование себестоимости, бухгалтерский учет, налоги, отчетность» / А. М.Петров. Москва, 2011. Сер. Полное руководство бухгалтера 